\title{
A new species of Lithobius (Monotarsobius) Verhoeff, I 905 (Lithobiomorpha, Lithobiidae) from China
}

\author{
Sujian Pei ${ }^{1, \dagger}$, Huiqin $\mathrm{Ma}^{2, \ddagger}$, Baojun Shi ${ }^{2, \S}$, Dayong Wu ${ }^{1,1}$, Wenjie Zhou ${ }^{1, \pi}$ \\ I Department of Life Sciences, Hengshui University, Hengshui, Hebei 053000, P. R. China 2 Scientific Rese- \\ arch Office, Hengshui University, Hengshui, Hebei 053000, P. R. China \\ † urn:lsid:zoobank.org:author:6A92478C-79B7-4330-AFCE-215C0D1E9796 \\ ¥ urn:lsid:zoobank.org:author:8A6B6C85-18B0-46DC-A8C5-3BEA704F63E3 \\ § urn:lsid:zoobank.org:author:B33C63D2-6E3B-4D10-80CB-904F258B72AF \\ | urn:lsid:zoobank.org:author:514BD91A-8783-4DE0-951A-7649B2A769EA \\ I urn:lsid:zoobank.org:author:20C1289C-41C2-4084-98AB-E63C69A11D61 \\ Corresponding author: Huiqin Ma (mhq008@yahoo.com)
}

Academic editor: Pavel Stoev | Received 20 December 2010 | Accepted 8 February 2011 | Published 23 February 2011

urn:lsid:zoobank.org:pub:B34A1744-0366-4B13-870B-E07EBCB248D0

Citation: Pei S, Ma H, Shi B, Wu D, Zhou W (2011) A new species of Lithobius (Monotarsobius) Verhoeff, 1905 (Lithobiomorpha, Lithobiidae) from China. ZooKeys 82: 59-66. doi: 10.3897/zookeys.82.823

\begin{abstract}
The present paper deals with a new species of the genus Lithobius Leach, 1814, L. (Monotarsobius) songi sp. n. (Lithobiomorpha: Lithobiidae) recently discovered in Hebei Province, China. Morphologically it resembles L. (M.) holstii (Pocock, 1895) from China and Japan but could be well distinguished from latter by having a Tömösváry's organ slightly smaller than the adjoining ocelli, different leg plectrotaxy and tridentate claw of female gonopods. A key to the Chinese Lithobius (Monotarsobius) species is presented.
\end{abstract}

\section{Keywords}

new species, Lithobius (Monotarsobius) songi sp. n., Lithobiidae, Hebei, China

\section{Introduction}

The subgenus Monotarsobius Verhoeff, 1905 of genus Lithobius Leach, 1814 is characterized by the presence of fused tarsi of legs $1-13$ and antennal articles fixed at 20 or thereabouts (Eason 1992). Presently, this subgenus comprises one hundred species known from Asia, Europe, and North Africa (Zapparoli 2006). Very little attention

Copyright S. Pei et al. This is an open access article distributed under the terms of the Creative Commons Attribution License, which permits unrestricted use, distribution, and reproduction in any medium, provided the original author and source are credited. 
has been paid to the study of Lithobiomorpha in China, with only 15 genera and 66 species having been recorded up to now (e.g. Takakuwa and Takashima 1949; Wang 1959, 1963; Zhang 1996; Ma et al. 2007a, b, 2008a, b). As regards the investigation of Lithobius (Monotarsobius) only 8 species have hitherto been recorded (cf. Trotzina 1895; Pocock 1895; Takakuwa 1940, 1941, 1942; Zalesskaja 1978; Wang and Mauriès 1996; Eason 1997; Chao 2005; Ma et al. 2009a, b). Takakuwa (1941) described $L$. (M.) obtusus and $L .(M$.$) ramulosus from Taiwan and later on (Takakuwa 1940, 1942)$ recorded also $L$. (M.) crassipes and $L$. (M.) holstii from the island. Zalesskaja (1978) recorded two other species, L. (M.) alticus and $L$. (M.) crassus from Xinjiang Autonomous Region. Eason (1997) recorded L. (M.) ferganensis from Xinjiang Autonomous Region, while Ma et al. (2009b) described $L$. (M.) subspinipes from Hainan and Hebei provinces. After a study of recently collected material from Hebei Province, we came across a new species of Lithobius (Monotarsobius), which is described below.

\section{Methods}

All specimens were hand-collected under stones. The material was examined with the aid of a Motic-C microscope, made in China. Colour description is based on specimens in $75 \%$ ethanol, and body length is measured from anterior margin of the cephalic plate to posterior end of telson. Type specimens are preserved in $75 \%$ ethanol and deposited in the College of Life Sciences, Hebei University, Baoding, China; some nontype material is deposited in the Department of Life Sciences, Hengshgui University, Hengshui, China. Terminology for external anatomy follows Bonato et al. (2010).

The following abbreviations are used in the text and tables: $\mathrm{T}, \mathrm{TT}=$ tergite, tergites; $\mathrm{S}, \mathrm{SS}=$ sternite, sternites; $\mathrm{C}=$ coxa, $\mathrm{t}=$ trochanter, $\mathrm{P}=$ prefemur, $\mathrm{F}=$ femur, $\mathrm{T}=$ tibia, $\mathrm{a}=$ anterior, $\mathrm{m}=$ median, $\mathrm{p}=$ posterior.

\section{Taxonomic part}

\section{Lithobiidae Newport, 1844}

Lithobius (Monotarsobius) songi sp. $\mathrm{n}$. urn:lsid:zoobank.org:act:9739FCCD-35E8-477E-AA81-22EA6B83F40A Figs 1-6

Etymology: The specific name is a patronym in honor of the zoologist Dr. Daxiang Song, Academician at the Chinese Academy of Sciences.

Material examined: Holotype: female (Fig. 1), body length $6.9 \mathrm{~mm}$, cephalic plate length $0.7 \mathrm{~mm}$, breadth $0.7 \mathrm{~mm}$; from Qingliangdian Town, Wuyi County, Hengshui City, Hebei Province, $37^{\circ} 06^{\prime} \mathrm{N} 115^{\circ} 08^{\prime} \mathrm{E}, 35$ m, 6 May 2005, leg. H. Ma. Paratypes: $2 q q, 1 \hat{\sigma}$, same data as holotype. 


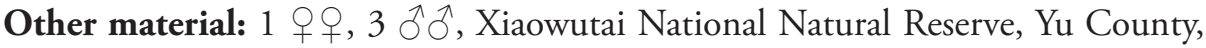
Zhangjiakou City, Hebei Province, 3954’N 11500’E, 1236 m, 21 August 2005, leg. Z. Zhang and H. Ma.

Diagnosis: A Lithobius (Monotarsobius) species with body length 5.9-6.9 mm, antennae composed of 19-21 articles, commonly 19+19; 6-7 ocelli on each side, commonly 6 , arranged in 2 irregular rows; Tömösváry's organ moderately small, slightly smaller than adjoining ocelli; $2+2$ coxosternal teeth; porodonts moderately slender and long, posterolateral to lateral tooth; posterior angles of all tergites without triangular projections; coxal pores 1222 , oval to round; female gonopods with $2+2$ moderately large, coniform spurs; terminal claw tridentate; male gonopods short and small, with 1-2 long setae on terminal segment.

Description: Body 5.9-6.9 mm long; cephalic plate 0.6-0.7 mm long, 0.6-0.7 $\mathrm{mm}$ wide. Colour: tergites and basal articles pale brown; transition to yellow brownish from the seventh or eighth articles onwards, the terminal article yellow brown; tergites pale chestnut; pleural region pale gray; SS pale orange; distal part of forcipules brown, the remaining part of forcipules, forcipular coxosternite and SS 14 and 15 pale yellowbrownish; all legs pale yellow-brownish, tarsi of all legs yellow-brown.

Antennae composed of 19+19-21+21 articles (Fig. 1), most often 19+19; basal article almost as long as wide, second one markedly longer than wide, succeeding articles gradually shortening; terminal article typically longer than wide, up to 2.3-2.9 times longer than wide. Antennal setation: abundant setae on antennal surface, but fewer setae on outer side and ventral and dorsal side in basal articles, gradual increase in density of setae to about fourth or fifth article, then more or less constant.

Cephalic plate smooth, convex, as long as broad, covered with sparse tiny setae; anterior part of the cephalic capsule with shallow median sulcus; pigment concentrated as close netlike veins, few short to long setae scattered along the marginal ridge; lateral marginal ridge continuous; posterior margin straight, without widening in middle part (Fig. 1).

Six-seven ocelli on each side of cephalic plate (Fig. 2), more often 6, arranged in 2 irregular rows; the terminal one larger, the ocelli near the dorsal slightly larger, the ocelli near the ventral slightly smaller; overhanging the lateral margin of the cephalic plate; ocelli gently bulging, translucent, usually darkly pigmented.

Tömösváry's organ moderately small (Fig. 2-To), nearly rounded, situated ventrad to anterolateral margin of cephalic pleurite, slightly smaller than the adjoining ocelli.

Coxosternite (Fig. 3) approximately trapezoidal, anterior margin moderately narrow with 2+2 comparatively sharp coxosternal teeth, median diastema relatively deep, V-shaped (Fig. 3); coxosternal shoulder lacking; porodonts lying posterolateral to the lateral tooth, comparely long and slender, without a bulge at the base. Moderately short to long setae sparsely scattered over the dental margin, comparatively long and thick near the dental margin.

All tergites moderately smooth, without wrinkles, backside slightly hunched, tiny setae scattered very sparsely over the surface; $\mathrm{T} 1$ generally subrectangular, anteriorly broadened; T 1 slightly narrower than T 3 and the cephalic plate, the latter slightly 


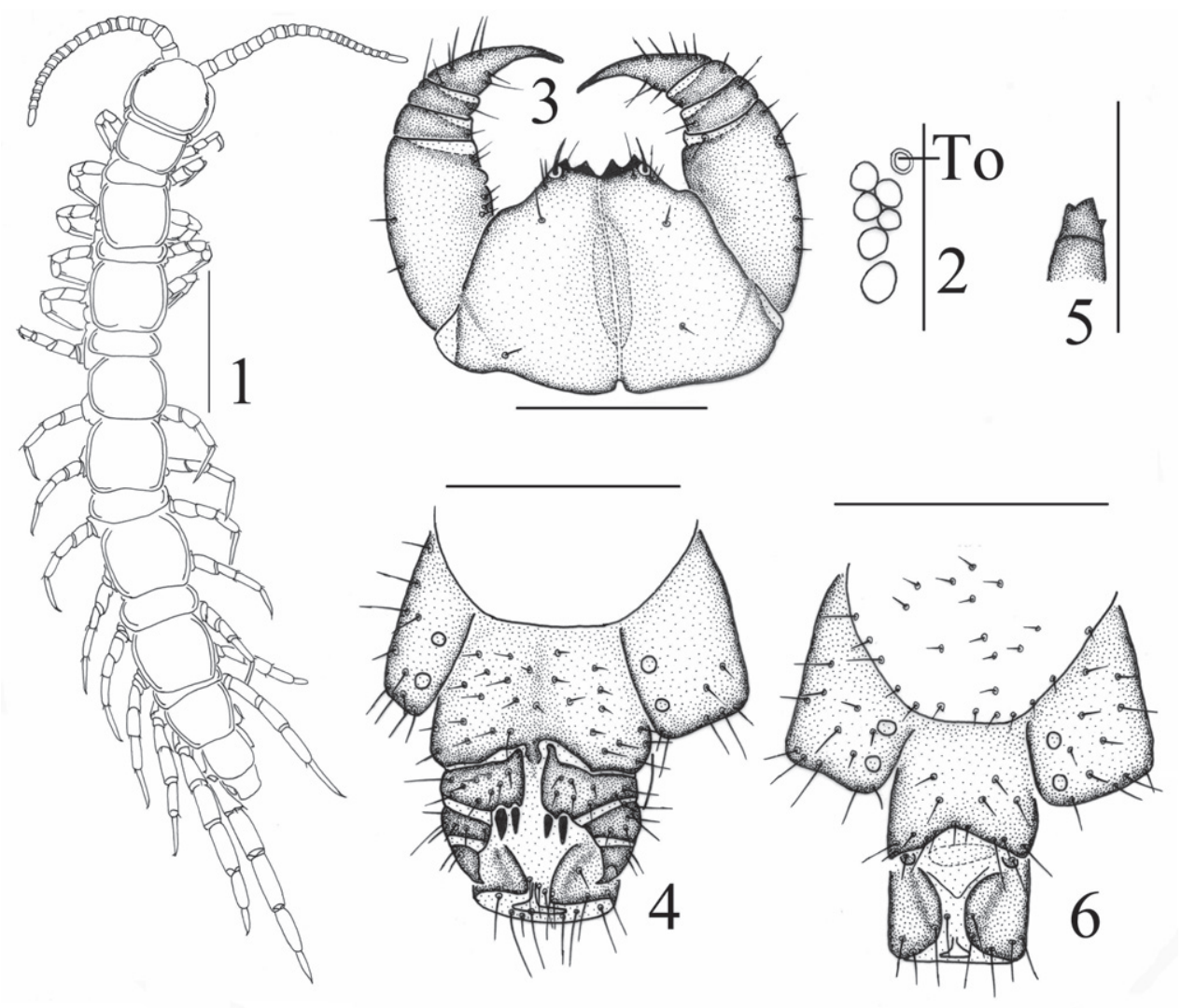

Figures I-6. L. (M.) songi sp. n., I-5 holotype, female: I habitus, dorsal view, scale $1 \mathrm{~mm} \mathbf{2}$ ocelli and Tömösváry's organ (To), lateral view, scale $250 \mu \mathrm{m} 3$ forcipular coxosternite, ventral view, scale $500 \mu \mathrm{m}$ 4 posterior segments and gonopods, ventral view, scale $500 \mu \mathrm{m} \mathbf{5}$ claw of gonopods, internal view, scale $250 \mu \mathrm{m} 6$ paratype, male: gonopods, ventral view, scale $250 \mu \mathrm{m}$.

wider than T3; lateral marginations of all tergites continuous, setae scattered sparsely along the lateral borders, more setae on anterior angles of tergites; posterior margin of TT 1, 3, 5, 7, 8, 10, 12 and 14 slightly concave; all tergites without posterior triangular projections (Fig. 1).

All sternites posterolaterally narrower than anterolaterally, generally trapeziform, moderately smooth, $2-4$ moderately setae on anterior part of each sternite, 2-3 longer setae on posterior part of each sternite.

Legs strong, tarsus 1-2 articulation fused on legs 1-13, well-defined on legs 14 and 15; claw moderately long and curved ventrad in all legs; accessory spur on both anterior and posterior side of claw of legs 1-14, anterior accessory spur moderately long and thicker, forming a moderately large angle with the claw; posterior accessory spur short and slender, forming a comparatively small angle with the claw; no accessory claws on leg 15; short to moderately long setae scattered over the surface of legs $1-13$, tarsi generally more setose, few setae on legs 14-15; legs 14 and 15 
markedly thickened, the male more thicken than the female, tarsus 1 about 4.0-5.3 times longer than wide, tarsus 2 about $67 \%-81 \%$ length of tarsus on legs 15. Legs' plectrotaxy: as in Table 1.

Coxal pores arranged in a row, ovate to round, moderately small, 1222. Pore-field set in a slightly shallow groove, 8 short to moderately long setae scattered sparsely over the margin of shallow groove.

Female $S 15$ posterolaterally narrower than anterolaterally, generally trapeziform, straight posteromedially; short to long setae scattered very sparsely over its surface and lateral margins. The sternite of genital segment usually well sclerotised, wider than long, posterior border moderately deeply concave between condyles of gonopods, except for a small, median approximately rhombic bulge, distally lightly sclerotised; short to moderately long setae evenly scattered over the surface of genital sternite except for middle and anterior parts. Female gonopods: basal article moderately broad, bearing 8 moderately long setae, arranged in 3 irregular rows, and $2+2$ small coniform spurs; inner spur slightly smaller and more anterior than the outer (Fig. 4); second article with 6 moderately long setae, arranged in 2 irregular rows; usually 3-4 moderately long setae on the surface of third article; terminal claw tridentate (Fig. 5), dorsal and ventral tooth about same in size.

Male S 15 posterolaterally narrower than anterolaterally, generally trapeziform, straight posteromedially; short to long setae scattered very sparsely over its surface and lateral margins. The sternite of genital segment usually well sclerotised, wider than long; comparatively long setae about evenly scattered on the ventral surface, slightly fewer near S15. Posterior margin of the sternite of the genital segment quite deeply concave between gonopods, no bulge medially; gonopods short and small, only a small hemispherical bulge, with 1-2 long setae on surface, terminal slightly sclerotised (Fig. 6).

Distribution: Known only from the Hebei Province (Hengshui and Zhangjiakou Cities), NE China.

Remarks: Having an eye composed of $6-7$ ocelli and about 20 antennal articles, the new species resembles L. (M.) holstii (Pocock, 1895) from China and Japan (Takakuwa

Table I. Legs' plectrotaxy of $L$. (M.) songi sp. n. Letters in brackets indicate variable spines.

\begin{tabular}{c|c|c|c|c|c|c|c|c|c|c}
\hline \multirow{2}{*}{ legs } & \multicolumn{9}{|c|}{ ventral } & \multicolumn{5}{c}{ dorsal } \\
\cline { 2 - 11 } & $\mathbf{C}$ & $\mathbf{t}$ & $\mathbf{P}$ & $\mathbf{F}$ & $\mathbf{T}$ & $\mathbf{C}$ & $\mathbf{t}$ & $\mathbf{P}$ & $\mathbf{F}$ & $\mathbf{T}$ \\
\hline 1 & & & $\mathrm{p}$ & $\mathrm{a}$ & $\mathrm{m}$ & & & $\mathrm{p}$ & $\mathrm{ap}$ & $\mathrm{a}$ \\
\hline 2 & & & $\mathrm{p}$ & $\mathrm{am}$ & $\mathrm{m}$ & & & $\mathrm{p}$ & $\mathrm{ap}$ & $\mathrm{ap}$ \\
\hline $3-9$ & & & & $\mathrm{am}$ & $\mathrm{m}$ & & & & $\mathrm{ap}$ & $\mathrm{ap}$ \\
\hline 10 & & & & $\mathrm{am}$ & $\mathrm{m}$ & & & & $\mathrm{p}$ & $\mathrm{ap}$ \\
\hline 11 & & & $(\mathrm{~m})$ & $\mathrm{am}$ & $\mathrm{m}$ & & & $\mathrm{p}$ & $\mathrm{p}$ & $\mathrm{p}$ \\
\hline 12 & & & $\mathrm{mp}$ & $\mathrm{am}$ & $\mathrm{am}$ & & & $\mathrm{p}$ & $\mathrm{p}$ & $\mathrm{p}$ \\
\hline 13 & & $(\mathrm{~m})$ & $\mathrm{mp}$ & $(\mathrm{a}) \mathrm{m}(\mathrm{p})$ & $\mathrm{m}$ & & & $\mathrm{mp}$ & $\mathrm{p}$ & $\mathrm{p}$ \\
\hline 14 & & $\mathrm{~m}$ & $\mathrm{mp}$ & $\mathrm{m}$ & & $\mathrm{m}$ & & $\mathrm{mp}$ & & \\
\hline 15 & & $\mathrm{~m}$ & $\mathrm{mp}$ & $\mathrm{m}$ & & $\mathrm{m}$ & & $\mathrm{mp}$ & & \\
\hline
\end{tabular}


1941). However, it is well distinguished from the latter by having Tömösváry’s organ slightly smaller than the adjoining ocelli, different leg plectrotaxy and tridentate claw of female gonopods (bidentate in $L$. (M.) holstii). It differs from L. (M.) subspinipes Ma et al., 2009 by having smaller Tömösváry's organ, different leg plectrotaxy and moderaterly setose legs (vs. only sparse setae in L. (M.) subspinipes).

Habitat preferences: The type series has been collected in a roadside of a mountain pine tree forest and under Chinese jujube trees in champaign environments.

\section{Key to the Chinese species of Lithobius (Monotarsobius)}

To assist in the identification of the Chinese species of L. (Monotarsobius), the following key is offered. This key emphasizes characters that can be examined without much dissection or high-magnification microscopy; moreover, these characters are specific to the taxa occurring in China.

1 Four ocelli on each side of cephalic plate, 17+17 antennal articles

L. (M.) crassus (Loksa, 1965)

- $\quad$ Five or more ocelli on each side of cephalic plate, not less than 18+18 anten-

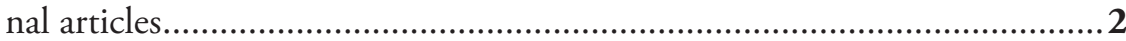

2 Five ocelli on each side of cephalic plate......... L. (M.) alticus (Loksa, 1965)

- Six or more ocelli on each side of cephalic plate ..................................... 3

3 With spines on the second article of female gonopod..............................4

- Without spines on the second article of female gonopod ..........................5

4 With two spines on the second article of female gonopod, six-ten ocelli on each side of cephalic plate, 1222-2222 coxal pores

L. (M.) ferganensis (Trotzina, 1894)

With three spines on the second article of female gonopod, eight-eleven ocelli on each side of cephalic plate, 2222-3443 coxal pores

L. (M.) crassipes L. Koch, 1862

5 Terminal claw of female gonopod simple

L. (M.) ramulosus (Takakuwa, 1941)

- $\quad$ Terminal claw of female gonopod bidentate or tridentate.......................6

6 Terminal claw of female gonopod tridentate ................................... 7

- Terminal claw of female gonopod bidentate ................................... 8

7 Tömösváry's organ slightly smaller than adjoining ocellus; terminal ocellus largest

L. (M.) songi sp. $\mathrm{n}$.

- Tömösváry's organ slightly larger than adjoining ocellus or about same in size; terminal two ocelli largest ................... L. (M.) subspinipes Ma et al., 2009

8 Tömösváry's organ larger than largest ocellus, antennae 20-25 articles

L. (M.) holstii (Pocock, 1895)

- Tömösváry's organ about same size as the adjoining ocelli, antennae 19 articles.

L. (M.) obtusus (Takakuwa, 1941) 


\section{Acknowledgements}

This project was supported by the National Natural Science Foundation of China (NSFC grant No. 30900131) and the Program for Research and Development of Science and Technology of Hebei Province (grant No. 09276724). We are grateful to Dr. Gregory D. Edgecombe, London, U.K. for his hospitality and everlasting help during our research. We also wish to thank Dr. Marzio Zapparoli, Viterbo, Italy, Dr. Rowland M. Shelley, North Carolina, USA, Dr. His-Te Shih, Taichung, China, and Dr. Nobuo Tsurusaki, Japan, for providing us with valuable literature related to this project. We express our gratitude to Dr. Zi-Zhong Yang and Dr. Zhi-Sheng Zhang for their help in preparing the paper.

\section{References}

Bonato L, Edgecombe GD, Lewis JGE, Minelli A, Pereira LA, Shelley RM, Zapparoli M (2010) A common terminology for the external anatomy of centipedes (Chilopoda). ZooKeys 69: $17-51$.

Chao JL (2005) Review and development of study on Chilopoda of Taiwan. Journal of Endangered Wild Animal 9: 33-41.

Eason EH (1992) On the taxonomy and geographical distribution of the Lithobiomorpha. In Meyer E, Thaler K, Schedl W (Eds) Advances in Myriapodology. Berichte des naturwissenschaftlich-medizinischen Vereins in Innsbruck, Supplement 10: 1-9.

Eason EH (1997) On some Lithobiomorpha from the mountains of Kirghizia and Kazakhstan (Chilopoda). Arthropoda Selecta 6: 117-121.

Ma H, Song D, Zhu M (2007a) A new genus and two new species of lithobiid centipedes (Chilopoda: Lithobiomorpha) from China. Zootaxa 1460: 25-34.

Ma H, Song D, Zhu M (2007b) A new species of the Genus Validifemur Ma, Song \& Zhu, 2007 (Chilopoda: Lithobiomorpha) from China. Arthropoda Selecta 16 (2): 1-6.

Ma H, Song D, Zhu M (2008a) A new species of the Genus Australobius Chamberlin, 1920 (Lithobiomorpha: Lithobiidae) from Tibet, China. Entomological News (19) 2: 171-177.

Ma H, Song D, Zhu M (2008b) A review of the Chinese species of Bothropolys Wood, 1862 (Chilopoda: Lithobiomorpha: Lithobiidae). Zootaxa 1786: 35-47.

Ma H, Song D, Zhu M (2009a) Two new species of the genus Bothropolys Wood, 1862 (Chilopoda: Lithobiomorpha: Lithobiidae) from China. Entomologica Fennica (19) 1: 248-256.

Ma H, Pei S, Zhu M, Zhang G, Liu L (2009b) A new species of Lithobius (Monotarsobius) Verhoeff, 1905 (Lithobiomorpha: Lithobiidae) from China. Entomological News (120)3: 313-318.

Pocock RI (1895) Report upon the Chilopoda and Diplopoda obtained by P. W. Bassett-Smith Esq. Surgeon R. N. and J. J. Walker Esq. R. N. during the cruise in the Chinese seas of H. M. S. "Penguin" Commander W. U. Moore commanding. Annals and Magazine of Natural History (6) 15: 346-372. 
Takakuwa Y (1940) Class Chilopoda, Epimorpha, Lithobiomorpha. Fauna Nipponica Vol. 9 Fas. 8 No. (3). Sanseido Book Store, Tokyo, 104 pp.

Takakuwa Y (1941) Über einige japanische Lithobiiden. Transactions of the Natural History Society of Formosa 31: 292-298.

Takakuwa Y (1942) Die Myriopoden aus Formosa Philippinien u.s.w.. Transactions of the Natural History Society of Formosa 32: 359-367.

Takakuwa Y, Takashima H (1949) Myriapods collected in Shansi, North China. Acta Arachnologica (11) 1-2: 51-69.

Trotzina A (1895) Vier neue Lithobius-Arten aus Central Asia. Horae Societatis Entomologicae Rossicae 28: 247-253.

Wang D, Mauriès JP (1996) Review and perspective of study on myriapodology of China. Acta Myriapodologica 169: 81-99.

Wang YHM (1959) On Chilopoda from Taiwan with a new lithobid. Quarterly Journal of the Taiwan Museum 12 (3-4): 195-199.

Wang YHM (1963) Millipedes and Chilopoda of Quemoy, Fukien Province and Taiwan island, Botel Tobago (Lan Yu), Taiwan Province and of Singapore. Quarterly Journal of the Taiwan Museum 16 (1-2): 89-96.

Zalesskaja NT (1978) Identification book of the lithobiomorph centipedes of the USSR (Chilopoda: Lithobiomorpha) [in Russian]. Moscow, Nauka Publ. House, 212 pp.

Zapparoli M (2006) Lithobiidae. In: Minelli A (Ed) ChiloBase. A world catalogue of Centipedes (Chilopoda), http://chilobase.bio.unipd.it

Zhang C (1996) Chilopoda: Lithobiomorpha. In: Wu S, Feng Z (Eds) The biology and human physiology in the Hoh Xil region. Sci. Press: Beijing, 244-251. 